\title{
Physical activity and cancer risk. Actual knowledge and possible biological mechanisms
}

\author{
Mihaela Jurdana \\ Faculty of Health Sciences, University of Primorska, Izola, Slovenia
}

Radiol Oncol 2021; 55(1): 7-17.

Received 11 July 2020

Accepted 25 September 2020

Correspondence to: Mihaela Jurdana, Ph.D., Faculty of Health Sciences, University of Primorska, Polje 42, SI-6310 Izola, Slovenija. Phone: +386 566264 69; Fax.: +386 56626480

Disclosure: No potential conflicts of interest were disclosed.

\begin{abstract}
Background. Scientific evidence has shown that an increase in regular physical activity is associated with a decrease in the development of many types of cancer. Potential mechanisms that link physical activity to reduced cancer risk include a decrease in systemic inflammation, hyperinsulinemia, insulin-like growth factor (IGF-I), sex hormones, pro-inflammatory leptin and other obesity-related cytokines, and a significant increase in anti-inflammatory adiponectin levels. In addition, physical activity improves immune function and the composition and diversity of the gastrointestinal microbiota. Moderate physical activity is important for cancer protection, but the most significant changes in the inflammatory profile are conferred by physical activity performed at higher intensities. Thus, there is a need for further investigation into the type, intensity, and duration of physical activity for the prevention of some types of cancer and the development of effective recommendations.
\end{abstract}

Conclusions. There is a strong evidence that physical activity of moderate to vigorous intensity protects against colon and breast cancer, and probably against cancer at all other sites.

Key words: physical activity; cancer; pro-inflammatory and anti-inflammatory cytokines; biological mechanisms

\section{Introduction}

The International Agency for Research on Cancer (IARC) reports that $25 \%$ of all cancer cases worldwide are caused by obesity and sedentary lifestyle. ${ }^{1}$ The idea of physical activity as a means for preventing cancer was explored in the early 20th century when two studies were published, suggesting that cancer mortality rates among men with different occupations decreased with increased physical activity. ${ }^{2,3}$ To date, the evidence of "skeletal muscle contraction effect" has been growing rapidly and many epidemiological studies on the role of physical activity in cancer prevention have been published. There is substantial evidence that greater physical activity levels lower the risk of some cancers. ${ }^{4}$ Recently gathered data has revealed that physical activity is associated with various site-specific cancers in many ways. In addition, preclinical studies have indicated that physical activity may similarly reduce cancer progression, its recurrence and have an impact on better survival rates. ${ }^{5}$ Furthermore, physical activity could decrease breast and colon cancer incidence with a linear dose response relationship indicating that engaging in longer exercise sessions or exercising with higher intensity will result in a greater reduction in cancer risk. ${ }^{4,6} \mathrm{New}$ evidence suggests that a comparable association might exist for other cancers, but for a complete evaluation, physical activity type, frequency and intensity need to be assessed. ${ }^{7}$ The World Cancer Research Fund's first report indicated a strong positive impact of physical activity in relation to colorectal and breast cancer. ${ }^{8,9}$ Furthermore, cancer risk varies within population subgroups such as a gender, age, race, body mass index, and physical fitness level. The effects of physical activity on the cancer outcome are associated with these parameters. ${ }^{6}$ The recent data of a multi-ethnic cohort study confirm the association 


\section{The intensity of physical activity}
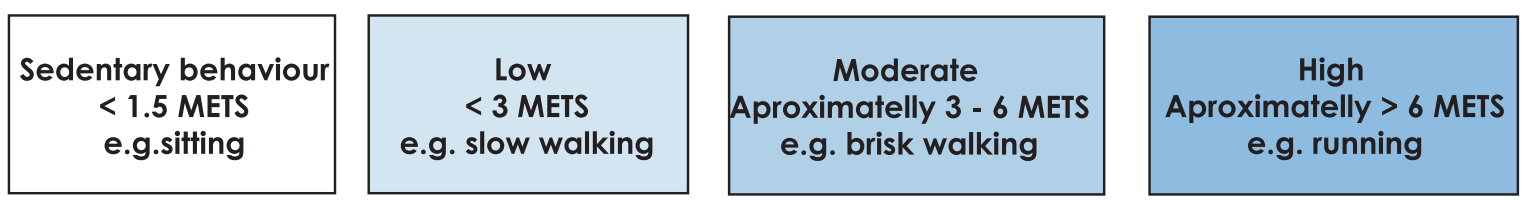

METs = metabolic equivalents

FIGURE 1. Levels of physical activity intensity (sedentary behaviour, low, moderate and vigorous or high).

between physical activity and colon cancer risk, and suggest possible differences in the strength of the association according to race and ethnicity. ${ }^{10}$

Several acceptable biological mechanisms link physical activity with cancer, including changes in sex hormones and other metabolic hormones, decrease in body fat mass and central adiposity, an increase in anti-inflammatory myokines exerting anti-inflammatory responses, and recently demonstrated changes in microbiota composition.

This review provides data from epidemiological studies on physical activity and cancer, and biological mechanisms to explain the association between physical activity and cancer.

\section{Physical activity recommendations}

Significant decreases in cancer incidence have been demonstrated among those who take into account the physical activity recommendations. ${ }^{11}$ The American Cancer Society (ACS), the World Cancer Research Fund/American Institute for Cancer Research (WCRF/AICR) and the World Health Organization (WHO) have published recommendations considered to reduce the risk of various diseases including cancer. ${ }^{12}$ In summary, the recommendations for adults of 150 minutes (2.5h) to 300 minutes (5h) of moderate physical activity, or at least 75 minutes (1.25 hours) to 150 minutes (2.5h) of vigorous physical activity per week, can reduce cancer risk. For additional health benefits, muscle-strengthening activities involving major muscle groups should be conducted on two or more days a week. ${ }^{12,13}$

To express the intensity level of physical activity, the rate of energy expenditure expressed as metabolic equivalents (METs) are commonly used. ${ }^{13}$ One MET is the rate of energy expenditure while sitting at rest, which for most people approximates an oxygen uptake of 3.5 millilitres per kilogram of body weight per minute. The energy expenditure of other activities is expressed in multiples of METs. A 3 MET activity expends 3 times the energy used at rest. The MET model is used in epidemiological studies and provides general medical thresholds and guidelines for a population. ${ }^{4}$

Based on the MET hours/week (MET h/w) model, physical activity can be classified as occupational physical activity (OPA) or leisure time physical activity (LTPA). OPA is low for sitting work, moderate for standing and walking work and high for manual work. LTPA is low for activities < 3MET, moderate for activities approximately 3-6 MET and vigorous or high intensity for activities $>6$ MET. ${ }^{13}$ (Figure 1). A recent study by Matthews et al., provides strong evidence that current recommendation levels of LTPA, both moderate to vigorous (7.5-15 MET h/w or 150-300 minutes/week) provide cancer (colon, breast, endometrial, kidney, myeloma, liver, non-Hodgkin lymphoma) protection in a dose dependent manner. ${ }^{4}$ Minor incidence of some cancer types seems to be correlated with vigorous LTPA. ${ }^{4}$

\section{Actual knowledge on the association between physical activity and cancer}

Several studies have been performed to assess the effect of LTPA in lowering cancer risk. There is convincing evidence of the beneficial effect of physical activity on the risk of colon and breast cancer and probable evidence for other cancers. ${ }^{4,6,7}$ Original scientific articles and systematic reviews (based largely on epidemiological studies consisting of large cohorts and case controls) have demonstrat- 
ed a dose-response relationship between physical activity and cancer risk. ${ }^{4,14}$

\section{Breast cancer}

In 1980 it was hypothesized that physical activity protects against breast cancer and many studies have confirmed this association risk. ${ }^{15}$

Physical activity is associated with a reduced risk of breast cancer incidence and better survival rates among women with breast cancer diagnosis. ${ }^{16}$ Physically active women had up to $20 \%$ lower risk incidence of breast cancer in comparison to inactive women, providing evidence that physical activity influences sex hormones, insulin resistance, and inflammatory adipokines. ${ }^{17,18}$ Another early case control study demonstrated a clear reduction of breast cancer in younger women during the reproductive period, who engaged in the recommended level of physical activity (3-6 MET h/w). ${ }^{19}$ Similarly, observational evidence suggests that regular physical activity reduces the risk of breast cancer incidence and mortality among obese menopausal and postmenopausal women. ${ }^{20-23}$

The Nurses' Health Study collected information over 29 years and reported that moderate or vigorous physical activity for 7 or more hours per week $(>6 \mathrm{MET} \mathrm{h} / \mathrm{w}$ ) compared to those who reported less than 1 hour per week ( $<3 \mathrm{MET} h / \mathrm{w}$ ) resulted in a $20 \%$ reduction in developing breast cancer. The association was similar in both premenopausal and postmenopausal women..$^{24,25}$

Campbell et al. state that regular exercise in association with weight reduction decreases the levels of sex hormones, as well as reducing breast cancer risk. ${ }^{26}$ In this study, more than 400 overweight to obese sedentary women, aged 50-75 years, were assigned to one of the following groups: a) moderate to vigorous intensity aerobic exercise only, b) diet only, c) moderate to vigorous intensity aerobic exercise and diet, and d) control. They found that physical activity among postmenopausal women might lower breast cancer risk by reducing fat mass, alongside a significantly greater decrease of estrogen and significantly increased sex hormonebinding globulin $(\mathrm{SHBG})^{27}$ which regulates the availability of free estrogen to hormone sensitive tissue by binding biologically active estrogen.

Taken together, these findings suggest that weight loss is the key factor linking alterations in diet or exercise to sex hormone changes. In the study conducted by Niehoff et al. 2019 the association between physical activity and breast cancer risk was examined in a large population of women with a family history of breast cancer. This demonstrated that physical activity was associated with reduced postmenopausal, but not premenopausal, breast cancer risk. ${ }^{28}$ The diversity of available data of physical activity and cancer association is due to population heterogeneity and the influence of breast cancer modifiable and non-modifiable factors, such as genetics, early age menarche, nulliparity, older age at first childbirth and breastfeeding. ${ }^{29}$ Although there is a proven link between physical activity and breast cancer, the type and dose of physical activity may have a varied effect. Physical activity can reduce the risk of breast cancer in women who engaged with moderate intensity levels. In addition, a greater decreased risk was found for vigorous intensity levels of physical activity with a stronger association in postmenopausal women. ${ }^{4}$ Risk reduction was observed among women who participated in physical activity during all periods in their lives.

\section{Colon and rectal cancer}

To date, the most definitive epidemiological studies have provided consistent evidence that physical activity is associated with a lower risk of colon cancer. ${ }^{8,30,31}$

A meta-analysis of numerous prospective studies, examining the association between physical activity of various intensity levels and the risk of developing colon and rectal cancer have been evaluated, showing that increased levels of physical activity considerably decreases the colon and rectal cancer risk. ${ }^{32}$ Moreover, others reported that higher levels of physical activity in colon cancer survivors have a minor possibility of cancer recurrence and improved survival compared to inactive survivors. ${ }^{33}$

Risk reduction for colon cancer in physically active individuals was greater in case control studies $(24 \%)$ in comparison with cohort studies $(17 \%)$. Similar results were found for OPA $(22 \%)$ and LTPA $(23 \%){ }^{34}$

The association between colon cancer and physical activity in case control studies showed an equally significant risk reduction for men and women $(24 \%)$ while in cohort studies this association was greater for men than for women. ${ }^{4,35,36}$ The effects of physical activity on colon and rectal cancer may be influenced by different parameters; physical activity type, intensity, frequency and duration, as well as vary by sex and race/ethnicity. ${ }^{37}$ The large multiethnic cohort study conducted by Park et al., demonstrated an inverse association be- 
tween moderate/vigorous activity and colorectal cancer risk, which appears to be stronger in men, especially among men with longer sitting time. ${ }^{10}$ A possible explanation of the diverse benefits between the sexes may reflect hormonal differences. ${ }^{10}$

The case-control study of Boyle considered 870 colorectal cancers cases (proximal colon, distal colon and rectal), compared 996 age and sex matched healthy controls, and analysed the timing and intensity of physical activity on sub site specific colorectal cancer risk, showing a strong reduction of distal colon cancer risk. ${ }^{38}$ Authors of this study demonstrated that physical activity with more than $6 \mathrm{MET} \mathrm{h} / \mathrm{w}$ was associated with a lower distal colon cancer risk by about $40 \%$, while an increase of physical activity to $18 \mathrm{MET} \mathrm{h} / \mathrm{w}$ further increased the percentage of cancer risk reduction. An association between physical activity and rectal cancer in participants exercising $6 \mathrm{MET} \mathrm{h/w}$ or more was also observed. In general, the overall data show no association between the total physical activity level and recreational physical activity and rectal cancer. Recently, it was found that LTPA was associated with a lower risk of both, colon and rectal cancer. ${ }^{22} \mathrm{~A}$ health initiative observational study found an inverse association between leisure time physical activity and rectal cancer, particularly, in postmenopausal women. ${ }^{39}$

Another case control study revealed that participants who spent more than ten years in sedentary work presented a greater risk of distal colon cancer and rectal cancer compared to those who never held sedentary work..$^{40}$ However, the risk was significantly reduced in participants who performed jobs requiring heavy activity. ${ }^{40}$

The health benefits of moderate to vigorous physical activity have been recently proposed to prevent colorectal cancer among people with longer sitting times. ${ }^{10}$ In addition, others confirm the protective role of moderate physical activity with the risk of the polyp's development and adenomas. ${ }^{41}$

\section{Other cancer sites}

Many studies reported on the association between physical activity and lower risk of several other site-specific types of cancer., ${ }^{9,42}$ Evidence is less consistent than for breast and colorectal cancer and can be classified as probable or possible. Regardless, patient data from nine cohort studies (US, European and Australian cohorts) including adult engagement in the recommended amounts of LTPA (moderate to intense activity) demonstrate, in addition to colon and breast cancer, also lower risk levels for endometrial and kidney cancer, liver cancer, lung, gastric and non-Hodgkin lymphoma (women only), ${ }^{4,42}$

\section{Endometrial cancer}

Previous meta-analysis studies of endometrial cancers found evidence of a decreased risk in moderately to vigorously physically active women. ${ }^{43}$ Many other studies investigated the influence of physical activity and body mass, since obesity is a strong risk factor for endometrial cancer as it is related to physical inactivity. ${ }^{44}$

\section{Bladder cancer}

The meta-analysis of many cohort studies and several case-control studies reported lower rates of bladder cancer for individuals with the highest level of recreational or OPA than those who were the least physically active. ${ }^{45}$ The LTPA of over one million individuals was associated with a reduced risk of bladder and kidney cancer. ${ }^{22}$

\section{Lung cancer}

Lung cancer has been less well studied than the cancers described above, but some epidemiological studies have revealed an association between physical activity and reduced cancer risk among former and current smokers. ${ }^{46}$

\section{Prostate cancer}

Evidence suggesting that physical activity can reduce prostate cancer risk is on the increase. Although rigorous physical activity may be needed to influence hormone levels involved in the etiology of this cancer. ${ }^{47}$

The data for several other cancers are limited and further research is needed in order to strengthen the hypothesis that physical activity reduces the development of cancer. ${ }^{22}$ Preliminary evidence suggests that higher levels of physical activity may influence cancer risk at several of these sites..$^{22}$

\section{Potential biological mechanisms in the relation between physical activity and cancer risk}

The most commonly hypothesized mechanisms proposed for physical activity and reduced cancer 


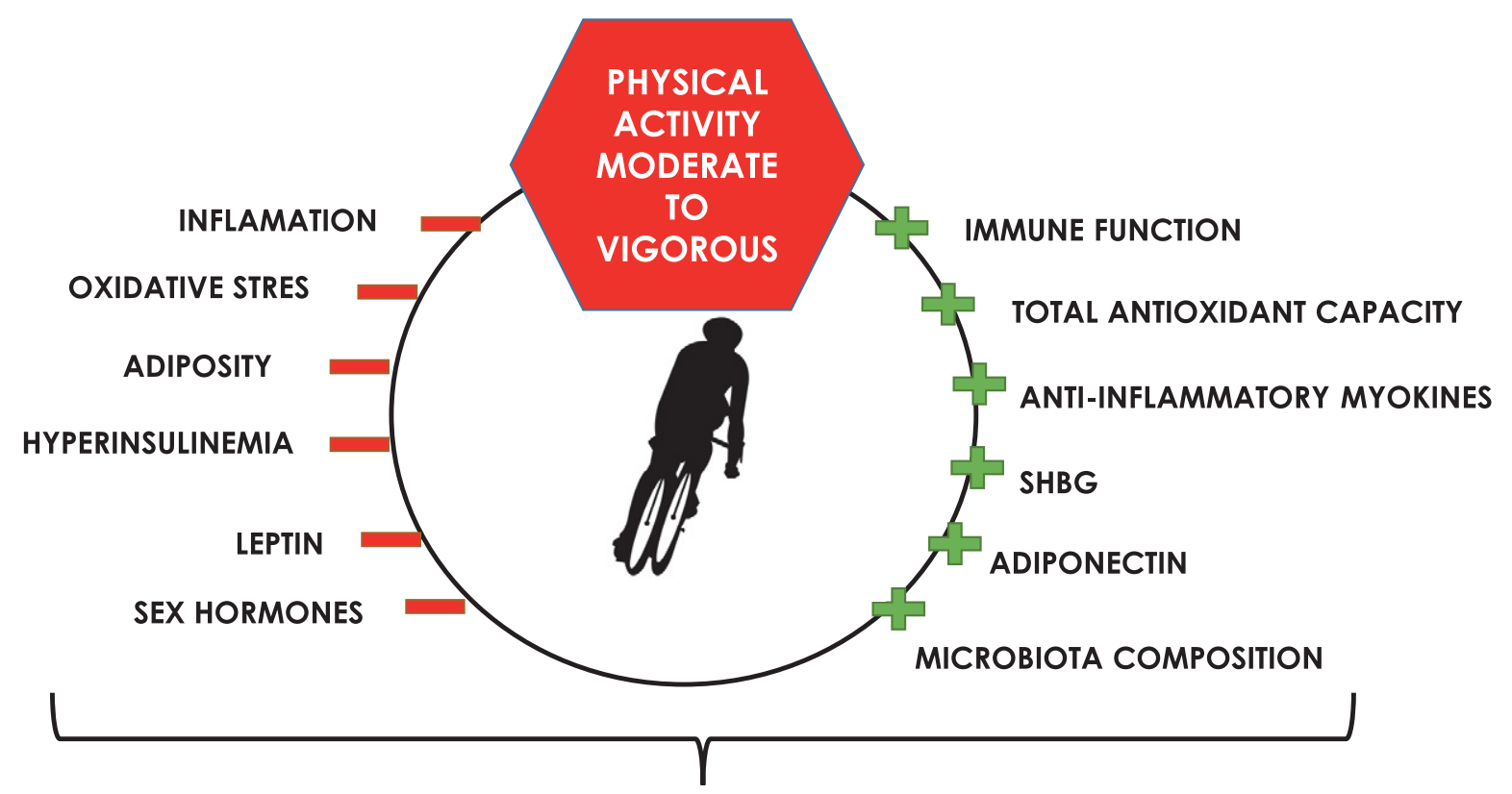

\section{DECREASE CANCER RISK}

SHBG = sex hormone-binding globulin

FIGURE 2. The effects of physical activity on cancer prevention.

Moderate to vigorous physical activity improves immune function, total antioxidant capacity, increases SHBG production and anti-inflammatory plasma adiponectin and improves gut microbiota composition. In addition, moderate to vigorous physical activity decreases systemic inflammation, oxidative stress, reduces adipose tissue and hyperinsulinemia, decreases inflammatory hormone leptin and regulates sex hormone levels.

risk are presented below. Moreover, the association between physical activity and gut microbiota composition in relation to cancer is described. The effects of physical activity on cancer prevention are summarized in Figure 2.

\section{Anti-inflammatory action of muscle derived myokines}

Skeletal muscle plays an important role in counteracting pro-inflammatory effects. During the past decade, it was identified as a secretory organ. ${ }^{48}$ Cytokines or other peptides that are produced, expressed and released by skeletal muscle and exert autocrine, paracrine or endocrine effects should be classified as 'myokines'. It has been suggested that myokines may contribute to exerciseinduced protection against several chronic diseases. ${ }^{48}$ Inflammation is a normal component of host defence; however, chronic low-grade inflammation is a key contributor in a range of chronic diseases and plays a critical role in cancer development and is crucial for the sustenance of the processes of tumorigenesis. ${ }^{49}$ Interleukin-1 (IL-1), tumor necrosis factor $\alpha$ (TNF- $\alpha$ ), and interleukin-6
(IL-6) are inflammatory cytokines that have been measured in relation to cancer. ${ }^{49}$ Increased levels of pro-inflammatory cytokines and a decrease in anti-inflammatory cytokines have been linked to increased cancer risk and a permanent presence of inflammatory cytokines also maintains an environment in which cancer cells can proliferate. ${ }^{49}$ Evidence suggests that regularly performed LTPA, moderate to vigorous may reduce markers of systemic inflammation. ${ }^{50}$ However, there is a substantial body of evidence that high-intensity or prolonged endurance training leads to increased oxidative stress that may result in a pro-inflammatory response from the immune system to protect the host tissue. ${ }^{51}$ In addition, an increase in the expression of pro-inflammatory cytokines can be crucial for long-term adaptive responses to exercise training. ${ }^{52}$ Although high-intensity endurance training can increase antioxidant enzyme activity and reduce markers of training-induced oxidative stress, very high training loads of elite and non-elite athletes participating in ultra-endurance competitions are associated with an acute reduction in antioxidant capacity and an increase in markers of oxidative stress. ${ }^{53}$ 
Skeletal muscle is an important source of antiinflammatory myokines, including muscle derived interleukin 6 (IL-6), interleukin 8 (IL-8), interleukin 15 (IL-15), and interleukin 1 receptor antagonist (IL-1ra), which act as antagonists to the generally pro-inflammatory cytokines. ${ }^{54}$

The pro-inflammatory TNF- $\alpha$ plays an important role in cancer promotion. ${ }^{55}$ TNF- $\alpha$ was originally identified as a factor that caused tumor necrosis in high concentrations; its activity at moderate levels can promote tumor growth. One of the key functions for TNF- $\alpha$ is to activate the pro-inflammatory transcription factor $(\mathrm{NF} \kappa \mathrm{B})$, involved in cancer pathogenesis. ${ }^{56}$

Interestingly, IL-6 produced by monocytes or macrophages acts as a pro-inflammatory response, whereas skeletal muscle derived IL- 6 acts as an anti-inflammatory response by reducing TNF- $\alpha$ concentration or $\mathrm{NF} \kappa \mathrm{B}$ activation. ${ }^{57}$

It turns out that regenerative or anti-inflammatory activities of interleukin-6 are mediated by classic signalling, whereas pro-inflammatory responses of interleukin- 6 are rather mediated by trans signaling. ${ }^{58}$ In classic signaling, interleukin-6 stimulates target cells via a membrane bound interleukin-6 receptor (IL-6R), which upon ligand binding associates with the signalling receptor protein gp130 and trigger the activation of the JAK/ STAT signalling pathway. In cells that express only gp130 but not IL-6R, IL-6 binds to the soluble IL-6R (sIL-6R) and the complex in turn binds to gp130 to trigger activation of intracellular signalling, known as trans signaling. ${ }^{58}$

Skeletal muscle IL-6 was the first identified myokine and, to date, the most studied myokine which is produced and released by contracting skeletal muscle fibres, exerting extensive antiinflammatory effects in other organs via an inflammatory (TNF- $\alpha$ ) independent pathway. ${ }^{59}$ IL-6 was discovered as a myokine because of the observation that IL-6 increases up to 100-fold in the circulation during and after physical activity. ${ }^{59}$ Therefore, the exercise release of IL-6 induces an increase in anti-inflammatory IL-1ra and IL-10. In most exercise-related studies, TNF- $\alpha$ does not change and is likely to be suppressed by the muscle derived IL-6, as demonstrated by a modest decrease of TNF- $\alpha$ after exercise. ${ }^{48}$ This confirms that anti-inflammatory effects of regular exercise can protect against systemic low-grade inflammation. The anti-inflammatory effects can be mediated by a reduction in visceral fat and body fat as well as by an anti-inflammatory environment through the release of myokines. ${ }^{59,60}$
Another skeletal muscle myokine, IL-15, has been identified as an anabolic factor in muscle growth and it appears to play an important role in fat metabolism. ${ }^{60}$ Interestingly, a negative association between plasma IL-15 concentration and abdominal fat mass was established, which supports the idea that muscle-expressed IL-15 may be involved in the reduction of visceral fat mass and may play an important role in the decrease of many cancer risks. ${ }^{57}$

Skeletal muscle is an endocrine organ, which, in addition to releasing myokines, also produces and secretes microRNAs into circulation. ${ }^{61}$ Loss of function microRNA experiments demonstrated that microRNAs have significant roles in the regulation of protein function in cancer, cancer cell proliferation and survival. ${ }^{61}$

\section{Immune function}

It has been demonstrated that moderate physical activity may enhance the immune function by increasing the number and activity of immune function cells such as neutrophils, eosinophils, monocytes and lymphocytes, and stimulate an increase in natural killer cells which have an important role in tumor suppression. ${ }^{5,62}$ Interestingly, regular moderate physical activity can increase the total antioxidant capacity of defence and be responsible for the elimination of reactive oxygen species (ROS). ${ }^{5}$ These highly reactive species are responsible for oxidative stress and play an important role in the progression of various types of human cancer. ${ }^{63}$ Moderate to vigorous physical activity can also provide a higher number of mitochondria in skeletal muscles that consequently provide a greater capacity to reduce oxidative stress. ${ }^{64}$ Indeed, each mitochondrion has a reduced oxidative load, and, as such, more electrons are directed to cytochrome oxidase instead of producing reactive oxygen species. ${ }^{65}$

\section{Hormones}

Regular moderate to vigorous intensities of physical activity influences the levels of biologically available sex hormones and decreases the incidence of hormone-related cancers, including breast cancer, endometrium, ovaries, and prostate cancer. ${ }^{66,67}$ Many studies have concluded that physical activity modifies metabolic hormone levels by lowering circulating fat, which produces the sex hormones responsible for the stimulatory effect on mammary glands and increases SHBG production, reducing 
their ability to influence target tissue. During menopause, the concentration of estrogens declines, but adipose tissue in obese women still produces estrogens after menopause. ${ }^{68}$ Physical activity responsible for reducing body fat mass, counteracts adipose tissue and is crucial for the reduction of breast cancer risk. ${ }^{68}$ Another study performed on premenopausal women demonstrated that regular physical activity and high LTPA reduce the concentration of estradiol and increase SHBG independent of obesity, thus indicating that the protective effect of exercise is not completely mediated by the changes in adiposity. ${ }^{69}$ Furthermore, excess levels of some androgens in men have been suggested to increase the risk of prostate cancer. Increased production of SHBG during physical activity may prevent prostate cancer development by decreasing the levels of biologically available testosterone. ${ }^{47}$

Regular moderate to vigorous physical activity affects cancer risk by reducing the levels of insulin and insulin growth factor-1 (IGF-1). ${ }^{70}$ High levels of (IGF-1) and insulin resistance have been responsible for an increased risk of various cancer types. $^{70}$ The epidemiological evidence between insulin levels and cancer risk is associated with hyperinsulinemia. Insulin is a powerful mitogen and is involved in glucose metabolism enhancing tumor development. Hyperinsulinemia promotes the synthesis and activity of (IGF-1), a mitogen that increases cellular proliferation, differentiation and transformation and inhibits apoptosis. ${ }^{71}$ Intervention strategies including regular physical activity reduce insulin levels, fasting glucose levels, decrease hepatic and muscle insulin resistance, and total IGF-1, increase glucose transporter protein and mRNA, increase activity of glycogen synthase and hexokinase, decrease release and increase clearance of free fatty acids, increase muscle glucose delivery because of increased muscle capillary density, and effect changes in muscle composition to increase glucose disposal. ${ }^{72}$ This proves that the mechanism involved is directly associated with skeletal muscle contraction during exercise.

\section{Adiposity}

Chronic low-grade inflammation in adiposity is associated with a higher risk of several cancer types. ${ }^{73-75}$ Adipose tissue as an endocrine organ which produces and releases a variety of proinflammatory cytokines such as (IL- 6), (TNF- $\alpha$ ), (CRP), leptin, and anti-inflammatory adiponectin. During exercise, in particular resistance training, skeletal muscle cells produce and express anti- inflammatory myokines, belonging to distinctly different families, responsible for reducing proinflammatory leptin, (IL-6) and (TNF- $\alpha$ ) secretion and significantly increase the adiponectin level. ${ }^{76}$ Some pro-inflammatory cytokines, such as the obesity hormone leptin, have a potential role in the development of a large variety of malignancies and are currently at the centre of the obesitycancer link. ${ }^{77}$ In humans, excessive adipose tissue is directly associated with elevated levels of leptin, which is significantly higher in women than in men, even after the adjustment for total body fat mass. ${ }^{78,79}$ One explanation for this tendency is a differential regulation of leptin expression by sex hormones; estrogens were observed to increase leptin levels, while testosterone was observed to decrease leptin levels. ${ }^{80}$ Leptin, in addition, can act as a mitogen and can increase the expression of anti-apoptotic proteins, inflammatory (TNF- $\alpha$ and IL-6), and angiogenic factors (VEGF). Interestingly, the effects of exercise, and particularly resistance exercise, can reduce leptin concertation, exerting an anti-inflammatory response. ${ }^{76,81-83}$ To date, the evidence that leptin can indeed be involved in the neoplastic processes has been provided by studies on breast and colorectal cancer, while limited studies are available for other cancer types. ${ }^{84}$

Moreover, adipose tissue adiponectin levels have been shown to exert anti-inflammatory actions and may thus counteract the increased cancer risk seen in obesity-induced inflammation. ${ }^{85}$ Plasma adiponectin levels are known to be associated with insulin sensitivity and the risk of developing metabolic disorders and malignancy. ${ }^{86}$ As exercise training improves insulin sensitivity and prevents the development of obesity related diseases, it has been proposed that exercise-induced improvement in insulin sensitivity is mediated through the regulation of plasma adiponectin levels. In addition, low serum adiponectin levels and high serum leptin levels are independent risks for cancer metastasis. ${ }^{87}$ Since physical inactivity is strongly linked with excess weight/obesity, and both are important risk factors for cancer development, regular physical activity appears to be important for the prevention of cancer development through reduction adiposity, in particular the metabolically active abdominal fat both of which are known to contribute to systemic inflammation. ${ }^{83}$

\section{The role of microbiota composition}

The human gastrointestinal tract (GIT) is colonized by trillions of microbial cells, and numerous studies 
have shown the importance of gut microbiota composition in several physiological and pathological processes, including local gastrointestinal cancer, as well as others such as distal cancer (head and neck, breast, oesophageal, pancreatic, and prostate cancer). ${ }^{88} \mathrm{~A}$ microbial imbalance or dysbiosis can be caused by several risk factors, such as aging, smoking, having an unhealthy diet, and inflammation that increases the host's risk for neoplastic transformation. ${ }^{89}$ Gut microbiota provides nutrients, regulates epithelial development, and affects the immune system. Additionally, an augmented microbial diversity is associated with improvement in the health status and the immune system..$^{90}$ It has been demonstrated that gut microbiota can be modulated by different factors. Recently, human and animal studies have revealed that aerobic exercise increases microbiota diversity, altering the bacterial composition and influencing the production of important metabolites of gut bacteria. ${ }^{91}$

Regular aerobic physical activity affects colon motility, provides a positive effect on the gut by reducing transient stool time and contact time between pathogens and the gastrointestinal mucosa layer.92 Physical activity may reduce prostaglandine production and inflammation and protect the integrity of the intestine. In this manner, physical activity prevents the risk of many diseases such as colon cancer, diverticulosis and other inflammatory diseases..$^{93}$ Other possible positive effects of exercise include elevated short-chain fatty acids (SCFAs) and immunoglobulin production and an increase in butyrate concentration. The increase of fecal butyrate has anti-carcinogenic and anti-inflammatory properties. ${ }^{94}$ In addition, exercise can prevent obesity and induce changes in microbiota composition and diversity, and potentially contribute to reducing weight and obesity-associated pathologies. ${ }^{95}$ Recently, it has been demonstrated that aerobic exercise training alters the gut microbiota and microbial-derived SCFA in sedentary lean and obese adults without any changes to dietary patterns. ${ }^{96}$ This evidence supports the idea that regular physical activity appears to be an important environmental factor that induces changes in microbial composition benefits for the host, and stimulates gut bacteria to produce substrates that protect against GIT disorders and colon cancer.

\section{Conclusions}

The epidemiological data for the beneficial effects of physical activity and cancer risk are being gath- ered rapidly and several possible mechanisms have been proposed to explain the link between physical activity and cancer. Physical activity can reduce the risk of various types of cancers by mechanisms including: decreasing markers of systemic inflammation by releasing anti-inflammatory myokines, improving insulin resistance, reducing leptin levels and hyperinsulinemia, increasing adiponectin levels and function of immune cells, decreasing circulating estrogen and androgen levels, and decreasing transient stool time and contact time between pathogens and the gastrointestinal mucosa layer. Discovering that skeletal muscle is an endocrine organ elucidated some of the proposed mechanisms.

Based on the current level of knowledge, some unexplained factors remain: existing evidence is limited to be able to support a specific dose of physical activity among a specific population subgroup, tailored for site-specific cancer reduction; how to measure precise physical activity; and how different type, dose and intensities of exercise are attributed to lowering certain cancer risks. General guidelines recommend 150 minutes of moderate physical activity or at least 75 of vigorous physical activity per week. ${ }^{11,97}$ The second report by the World Cancer Research Fund (WRCF) states that "more physical activity is better". Although any dose of physical activity is important for the reduction of cancer risk; to date, data from numerous studies have reported that higher levels of physical activity (150-300 minutes per week or 7-15 MET $\mathrm{h} / \mathrm{w}$ ) in particular, making vigorous is important for cancer prevention. ${ }^{4}$

\section{References}

1. Vainio $H$, Kaaks R, Bianchini F. Weight control and physical activity in cancer prevention: international evaluation of the evidence. Eur J Cancer Prev 2002; 11 (Suppl 2): S94-100.

2. Cherry T. A theory of cancer. Med J Australia 1922; 1: 425-38.

3. Sivertsen I, Dahlstrom AW. The relation of muscular activity to carcinoma: a preliminary report. J Cancer Res 1922; 6: 365-78.

4. Matthews CE, Moore SC, Arem H, Cook MB, Trabert B, Håkansson N, et al. Amount and intensity of leisure-time physical activity and lower cancer risk. J Clin Oncol 2020; 38: 686-97. doi: 10.1200/JCO.19.02407

5. Assi $M$, Dufresne $S$, Rébillard $A$. Exercise shapes redox signaling in cancer. Redox Biol 2020; 35: 101439. doi: 10.1016/j.redox.2020.101439

6. Friedenreich $\mathrm{CM}$. Physical activity and breast cancer: review of the epidemiologic evidence and biologic mechanisms. Recent Results Cancer Res 2011; 188: 125-39. doi: 10.1007/978-3-642-10858-7_11

7. Thune I, Furberg AS. Physical activity and cancer risk: dose-response and cancer, all sites and site-specific. Med Sci Sports Exerc 2001; 33: S530-S610. doi: 10.1097/00005768-200106001-00025 
8. World Cancer Research Fund and the American Institute for Cancer Research. Food, nutrition, physical activity and the prevention of cancer: a global perspective. Washington DC: American Institute for Cancer Research; 1997.

9. Wiseman M. The second World Cancer Research Fund/American Institute for Cancer Research expert report. Food, nutrition, physical activity, and the prevention of cancer: a global perspective. Proc Nutr Soc 2008; 67: 253-56. doi: 10.1017/\$002966510800712X

10. Park SY, Wilkens LR, Haiman CA, Le Marchand L. Physical activity and colorectal cancer risk by sex, race/ethnicity, and subsite: the multiethnic cohort study. Cancer Prev Res 2019; 12: 315-26. doi: 10.1158/1940-6207. CAPR-18-0452

11. Kabat GC, Matthews CE, Kamensky V, Hollenbeck AR, Rohan TE. Adherence to cancer prevention guidelines and cancer incidence, cancer mortality, and total mortality: a prospective cohort study. Am J Clin Nutr 2015; 101: 55869. doi: 10.3945/ajcn.114.094854

12. Coletta AM, Marquez G, Thomas P, Thoman W, Bevers T, Brewsteret AM, et al. Clinical factors associated with adherence to aerobic and resistance physical activity guidelines among cancer prevention patients and survivors. PLoS One 2019; 14: e0220814. doi: 10.1371/journal.pone.0220814.

13. Ainsworth BE, Haskell WL, Whitt MC, Irwin ML, Swartz AM, Strath SJ, et al. Compendium of physical activities: an update of activity codes and MET intensities. Med Sci Sports Exerc 2000; 32: S498-516. doi: 10.1097/00005768200009001-00009

14. Rezende LFM, Sá TH, Markozannes G, Rey-López JP, Lee IM, Tsilidis KK, et al. Physical activity and cancer: an umbrella review of the literature including 22 major anatomical sites and 770000 cancer cases. Br J Sports Med 2018: 52: 826-33. doi: 10.1136/bjsports-2017-098391

15. Wu Y, Zhang D, Kang S. Physical activity and risk of breast cancer: a metaanalysis of prospective studies. Breast Cancer Res Treat 2013; 137: 869-82. doi: 10.1007/s10549-012-2396-7

16. Spei ME, Samoli E, Bravi F, La Vecchia C, Bamia C, Benetou V. Physical activity in breast cancer survivors: a systematic review and meta-analysis on overall and breast cancer survival. Breast 2019; 44: 144-52. doi: 10.1016/j. breast.2019.02.001

17. de Boer MC, Wörner EA, Verlaan D, van Leeuwen PA. The mechanisms and effects of physical activity on breast cancer. Clin Breast Cancer 2017; 17: 272-78. doi: 10.1016/j.clbc.2017.01.006

18. Friedenreich CM, Cust AE. Physical activity and breast cancer risk: impact of timing, type and dose of activity and population subgroup effects. $\mathrm{Br} J$ Sports Med 2008; 42: 636-47. doi: 10.1136/bjsm.2006.029132

19. Bernstein L, Henderson BE, Hanisch R, Sullivan-Halley J, Rosset RK. Physical exercise and reduced risk of breast cancer in young women. J Natl Cancer Inst 1994; 86: 1403-08. doi: 10.1093/jnci/86.18.1403

20. Kushi LH, Doyle C, McCullough M, Rock CL, Demark-Wahnefried W, Bandera $\mathrm{EV}$, et al. American Cancer Society guidelines on nutrition and physical activity for cancer prevention: reducing the risk of cancer with healthy food choices and physical activity. CA Cancer J Clin 2012; 62: 30-67. doi: 10.3322/ caac. 20140

21. Clinton SK, Giovannucci EL \& Hursting SD. The World Cancer Research Fund/ American Institute for Cancer Research third expert report on diet, nutrition, physical activity, and cancer: impact and future directions. J Nutr 2020; 150(4):663-71. doi: 10.1093/jn/nxz268

22. Moore SC, Lee IM, Weiderpass E, Campbell PT, Sampson JN, Kitaharaet $\mathrm{CM}$ et al. Association of leisure-time physical activity with risk of 26 types of cancer in 1.44 million adults. JAMA Intern Med 2016; 176: 816-25. doi: 10.1001/jamainternmed.2016.1548

23. Zhong S, Jiang T, Ma T, Zhang X, Tang J, Chen W, et al. Association between physical activity and mortality in breast cancer: a meta-analysis of cohort studies. Eur J Epidemiol 2014; 29: 391-404. doi: 10.1007/s10654-0149916-1

24. Colditz GA, Hankinson SE. The nurses' health study: lifestyle and health among women. Nat Rev Cancer 2005; 5: 388-96. doi: 10.1038/nrc1608

25. Chan DS, Vieira AR, Aune D, Bandera EV, Greenwood DC, McTiernan A, et al. Body mass index and survival in women with breast cancer-systematic literature review and meta-analysis of 82 follow-up studies. Ann Oncol 2014; 25: 1901-14. doi: 10.1093/annonc/mdu042
26. Campbell KL, Foster-Schubert KE, Alfano CM, Wang CC, Wang CY, Duggan $\mathrm{CR}$, et al. Reduced-calorie dietary weight loss, exercise, and sex hormones in postmenopausal women: randomized controlled trial. J Clin Oncol 2012; 30: 2314-26. doi: 10.1200/JCO.2011.37.9792

27. Cauley JA, Gutai JP, Kuller LH, LeDonne D, Powell JG. The epidemiology of serum sex hormones in postmenopausal women. Am J Epidemiol 1989; 129: 1120-31. doi: 10.1093/oxfordjournals.aje.a115234

28. Niehoff NM, Nichols HB, Zhao S, White AJ, Sandler DP. Adult physical activity and breast cancer risk in women with a family history of breast cancer. Cancer Epidemiol Biomarkers Prev 2019; 28: 51-8. doi: 10.1158/1055-9965. EPI-18-0674

29. Ahmed Z. Risk factors in breast cancer: can we change something. MOJ Surg 2019; 7: 4-8. doi: 10.15406/mojs.2019.07.00154

30. Courneya KS, Booth CM, Gill S, O'Brien P, Vardy J, Friedenreich CM, et al. The colon health and life-long exercise change trial: a randomized trial of the National Cancer Institute of Canada Clinical Trials Group. Curr Oncol 2008; 15: 279-85. doi: $10.3747 /$ co.v15i6.378

31. Kerr J, Anderson C, Lippman SM. Physical activity, sedentary behaviour, diet, and cancer: an update and emerging new evidence. Lancet Oncol 2017; 18: e457-71. doi: 10.1016/S1470-2045(17)30411-4

32. Oruç Z, Kaplan MA. Effect of exercise on colorectal cancer prevention and treatment. World J Gastrointest Oncol 2019; 11: 348-66. doi: 10.4251/wjgo. v11.i5.348

33. Meyerhardt JA, Ogino S, Kirkner GJ, Chan AT, Wolpin B, Ng K, et al. Interaction of molecular markers and physical activity on mortality in patients with colon cancer. Clin Cancer Res 2009; 15: 5931-36. doi: 10.1158/1078-0432. CCR-09-0496

34. Friedenreich CM, Neilson HK, Lynch BM. State of the epidemiological evidence on physical activity and cancer prevention. Eur J Cancer 2010; 46: 2593-604. doi: 10.1016/j.ejca.2010.07.028

35. Wolin KY, Yan Y, Colditz GA, Lee IM. Physical activity and colon cancer prevention: a meta-analysis. Br J Cancer 2009; 100: 611-16. doi: 10.1038/ sj.bjc. 6604917

36. Wolin KY, Tuchman H. Physical activity and gastrointestinal cancer prevention. Recent Results Cancer Res 2011; 186: 73-100. doi: 10.1007/978-3642-04231-7_4

37. Brown JC, Winters-Stone K, Lee A, Schmitz KH. Cancer, physical activity, and exercise. Compr Physiol 2012; 2: 2775-809. doi: 10.1002/cphy.c120005

38. Boyle T, Heyworth J, Bull F, McKerracher S, Platell C, Fritschi L. Timing and intensity of recreational physical activity and the risk of subsite-specific colorectal cancer. Cancer Causes Control 2011; 22: 1647-58. doi: 10.1007/ s10552-011-9841-5

39. Gorczyca AM, Eaton CB, LaMonte MJ, Garcia DO, Johnston JD, He K, et al. Association of physical activity and sitting time with incident colorectal cancer in postmenopausal women. Eur J Cancer Prev 2018; 27: 331-38. doi: 10.1097/CEJ.000000000000035

40. Boyle T, Fritschi L, Heyworth J, Bull F. Long-term sedentary work and the risk of subsite-specific colorectal cancer. Am J Epidemiol 2011; 173: 1183-91. doi: 10.1093/aje/kwq513

41. Sanchez NF, Stierman B, Saab S, Mahajan D, Yeung H, Francois F. Physical activity reduces risk for colon polyps in a multiethnic colorectal cancer screening population. BMC Res Notes 2012; 5: 312. doi: 10.1186/1756-0500-5-312

42. Physical Activity Guidelines Advisory Committee. Physical Activity Guidelines Advisory Committee scientific report, 2018. Washington, DC: U.S. Department of Health and Human Services; 2018.

43. Schmid D, Behrens G, Keimling M, Jochem C, Ricci C, Leitzmann M. A systematic review and meta-analysis of physical activity and endometrial cancer risk. Eur J Epidemiol 2015; 30: 397-412. doi: 10.1007/s10654-0150017-6

44. Friedenreich C, Cust A, Lahmann PH, Steindorf K, Boutron-Ruault MC, Clavel-Chapelon F, et al. Physical activity and risk of endometrial cancer: the European prospective investigation into cancer and nutrition. Int J Cancer 2007; 121: 347-55. doi: 10.1002/ijc.22676

45. Keimling M, Behrens G, Schmid D, Jochem C, Leitzmann MF. The association between physical activity and bladder cancer: systematic review and metaanalysis. Br J Cancer 2014; 110: 1862-70. doi: 10.1038/bjc.2014.77 
46. Schmid D, Ricci C, Behrens G, Leitzmann MF. Does smoking influence the physical activity and lung cancer relation? A systematic review and meta-analysis. Eur J Epidemiol 2016; 31: 1173-90. doi: 10.1007/s10654016-0186-y

47. Shephard RJ. Physical activity and prostate cancer: an updated review. Sports Med 2017; 47: 1055-73. doi: 10.1007/s40279-016-0648-0

48. Pedersen BK. Muscle as a secretory organ. Compr Physiol 2013; 3: 1337-62. doi: $10.1002 /$ cphy.c120033

49. Hunter P. The inflammation theory of disease. The growing realization that chronic inflammation is crucial in many diseases opens new avenues for treatment. EMBO Rep 2012; 13: 968-70. doi: 10.1038/embor.2012.142

50. Woods JA, Vieira VJ, Keylock KT. Exercise, inflammation, and innate im munity. Immunol Allergy Clin North Am 2009; 29: 381-93. doi: 10.1016/j. iac.2009.02.011

51. Allen J, Sun $Y$, Woods JA. Exercise and the regulation of inflammatory responses. Prog Mol Biol Transl Sci 2015; 135: 337-54. doi: 10.1016/ bs.pmbts.2015.07.003

52. Cerqueira É, Marinho DA, Neiva HP, Lourenço O. Inflammatory effects of high and moderate intensity exercise - a systematic review. Front Physiol 2020; 10: 1550. doi: 10.3389/fphys.2019.01550

53. Neubauer O, König D, Kern N, Nics L, Wagner KH. No indications of persistent oxidative stress in response to an ironman triathlon. Med Sci Sports Exerc 2008; 40: 2119-28. doi: 10.1249/MSS.0b013e3181824dab

54. Ostrowski K, Rohde T, Asp S, Schjerling P, Pedersen BK. Pro and anti-inflammatory cytokine balance in strenuous exercise in humans. J Physiol 1999; 515: 287-91. doi: 10.1111/j.1469-7793.1999.287ad.x

55. Balkwill F. Tumour necrosis factor and cancer. Nat Rev Cancer 2009; 9: 361-71. doi: $10.1038 / \mathrm{nrc} 2628$

56. Xia L, Tan S, Zhou Y, Lin J, Wang H, Oyang L, et al. Role of the NFkB-signaling pathway in cancer. Onco Targets Ther 2018; 11: 2063-73. doi: 10.2147/ OTT.S161109

57. Brandt C, Pedersen BK. The role of exercise-induced myokines in muscle homeostasis and the defense against chronic diseases. J Biomed Biotechno 2010; 2010: 520258. doi: 10.1155/2010/520258

58. Scheller J, Chalaris A, Schmidt-Arras D, Rose-John S. The pro- and antiinflammatory properties of the cytokine interleukin-6. Biochim Biophys Acto 2011; 1813: 878-88. doi: 10.1016/j.bbamcr.2011.01.034

59. Pedersen BK, Febbraio MA. Muscle as an endocrine organ: focus on muscle-derived interleukin-6. Physiol Rev 2008; 88: 1379-406. doi: 10.1152/ physrev. 90100.2007

60. Nielsen AR, Pedersen BK. The biological roles of exercise-induced cytokines: IL-6, IL-8, and IL-15. Appl Physiol Nutr Metab 2007; 32: 833-39. doi 10.1139/H07-054

61. Dufresne S, Rébillard A, Muti P, Friedenreich CM, Brenner DR. A review of physical activity and circulating miRNA expression: implications in cance risk and progression. Cancer Epidemiol Biomarkers Prev 2018; 27: 11-24. doi: 10.1158/1055-9965.EPI-16-0969

62. Shephard RJ, Shek PN. Associations between physical activity and susceptibility to cancer: possible mechanisms. Sports Med 1998; 26: 293-315. doi: 10.2165/00007256-199826050-00002

63. Toyokuni S. Oxidative stress and cancer: the role of redox regulation. Biotherapy 1998; 11: 147-54. doi: 10.1023/a:1007934229968

64. Sotgia F, Martinez-Outschoorn UE, Lisanti MP. Mitochondrial oxidative stress drives tumor progression and metastasis: should we use antioxidants as a key component of cancer treatment and prevention? BMC Med 2011; 9: 62. doi: 10.1186/1741-7015-9-62

65. Di Meo S, Venditti P. Mitochondria in exercise-induced oxidative stress. Bio Signals Recept 2001; 10: 125-40. doi: 10.1159/000046880

66. Friedenreich $\mathrm{CM}$, Orenstein MR. Physical activity and cancer prevention: etiologic evidence and biological mechanisms. J Nutr 2002; 132 (11 Suppl): 3456S-64S. doi: 10.1093/jn/132.11.3456S

67. Kruk J, Aboul-Enein HY. Physical activity in the prevention of cancer. Asian Pac J Cancer Prev 2006; 7: 11-21.

68. Friedenreich $\mathrm{CM}$. Physical activity and breast cancer risk: the effect of menopausal status. Exerc Sport Sci Rev 2004; 32: 180-4. doi: 10.1097/00003677200410000-00010
69. Emaus A, Veierød MB, Furberg AS, Espetvedt S, Friedenreich C, Ellisonet PT, et al. Physical activity, heart rate, metabolic profile, and estradiol in premenopausal women. Med Sci Sports Exerc 2008; 40: 1022-30. doi: 10.1249/ MSS.0b013e318167411f

70. Kaaks R, Lukanova A. Energy balance and cancer: the role of insulin and insulin-like growth factor-I. Proc Nutr Soc 2001; 60: 91-106. doi: 10.1079/ pns200070

71. Tsujimoto T, Kajio $H$, Sugiyama T. Association between hyperinsulinemia and increased risk of cancer death in nonobese and obese people: a population-based observational study. Int J Cancer 2017; 141: 102-11. doi: 10.1002/ijc.30729

72. Fairey AS, Courneya KS, Field CJ, Bell GJ, Jones LW, Mackey JR. Effects of exercise training on fasting insulin, insulin resistance, insulin-like growth factors, and insulin-like growth factor binding proteins in postmenopausal breast cancer survivors: a randomized controlled trial. Cancer Epidemiol Biomarkers Prev 2003; 12: 721-27.

73. Coussens LM, Werb Z. Inflammation and cancer. Nature 2002; 420: 860-67. doi: $10.1038 /$ nature01322

74. Divella R, De Luca R, Abbate I, Naglieri E, Daniele A. Obesity and cancer: the role of adipose tissue and adipo-cytokines-induced chronic inflammation. $J$ Cancer 2016; 7: 2346-59. doi: 10.7150/jca.16884

75. van Kruijsdijk RC, van der Wall E, Visseren FL. Obesity and cancer: the role of dysfunctional adipose tissue. Cancer Epidemiol Biomarkers Prev 2009; 18: 2569-78. doi: 10.1158/1055-9965.EPI-09-0372

76. Bouassida A, Chamari K, Zaouali M, Feki Y, Zbidi A, Tabka Z. Review on leptin and adiponectin responses and adaptations to acute and chronic exercise. Br J Sports Med 2010; 44: 620-30. doi: 10.1136/bjsm.2008.046151

77. Tilg $\mathrm{H}$, Moschen AR. Mechanisms behind the link between obesity and gastrointestinal cancers. Best Pract Res Clin Gastroenterol 2014; 28: 599-610. doi: 10.1016/j.bpg.2014.07.006

78. Maffei M, Halaas J, Ravussin E, Pratley RE, Lee GH, Zhang Y, et al. 1995. Leptin levels in human and rodent: measurement of plasma leptin and $\mathrm{Ob}$ RNA in obese and weight-reduced subjects. Nat Med 1995; 1: 1155-61. doi: 10.1038/nm1195-1155

79. Havel PJ, Kasim-Karakas S, Dubuc GR, Mueller W, Phinney SD. Gender differences in plasma leptin concentrations. Nat Med 1996; 2: 949-50. doi: $10.1038 / \mathrm{nm0996}-949 \mathrm{~b}$

80. Thomas T, Burguera B, Melton $\sqcup$ 3rd, Atkinson EJ, O'Fallon WM, Riggs BL, et al. Relationship of serum leptin levels with body composition and sex steroid and insulin levels in men and women. Metabolism 2000; 49: 1278-84. doi: $10.1053 /$ meta. 2000.9519

81. Pérusse L, Collier G, Gagnon J, Leon AS, Rao DC, Skinner JS, et al. Acute and chronic effects of exercise on leptin levels in humans. J Appl Physiol 1997; 83: 5-10. doi: 10.1152/jappl.1997.83.1.5

82. Nuri $R$, Moghaddasi M, Darvishi $H$, Izadpanah A. Effect of aerobic exercise on leptin and ghrelin in patients with colorectal cancer. J Can Res Ther 2016; 12: 169-74. doi: 10.4103/0973-1482.155982

83. de Salles BF, Simão R, Fleck SJ, Dias I, Kraemer-Aguiar LG, Bouskela E. Effects of resistance training on cytokines. Int J Sports Med 2010; 31: 441-50. doi: 10.1055/s-0030-125199

84. Garofalo C, Surmacz E. Leptin and cancer. J Cell Physiol 2006; 207: 12-22. doi: $10.1002 / j c p .20472$

85. Dalamaga M, Diakopoulos KN, Mantzoros CS. The role of adiponectin in cancer: a review of current evidence. Endocr Rev 2012; 33: 547-94. doi: 10.1210/er.2011-1015

86. Iwabu M, Okada-Iwabu M, Yamauchi T, Kadowaki T. Adiponectin/AdipoR research and its implications for lifestyle-related diseases. Front Cardiovasc Med 2019; 6: 116. doi: 10.3389/fcrm.2019.00116

87. Hou WK, Xu YX, Yu T, Zhang L, Zhang WW, Fu CL, et al. Adipocytokines and breast cancer risk. Chin Med J (Engl) 2007; 120: 1592-96.

88. Goodman B, Gardner H. The microbiome and cancer. J Pathol 2018; 244: 667-76. doi: 10.1002/path.5047

89. Zitvogel L, Galluzzi L, Viaud S, Vétizou M, Daillère R, Merad M, et al. Cance and the gut microbiota: an unexpected link. Sci Transl Med 2015; 7: $271 \mathrm{ps1.}$ doi: $10.1126 /$ scitranslmed. 3010473 
90. Eckburg PB, Bik EM, Bernstein CN, Purdom E, Dethlefsen L, Sargentet M, et al. Diversity of the human intestinal microbial flora. Science 2005; 308: 1635-38. doi: 10.1126/science.1110591

91. Welly RJ, Liu TW, Zidon TM, Rowles JL, Park YM, Smith TN, et al. Comparison of diet versus exercise on metabolic function and gut microbiota in obese rats. Med Sci Sports Exerc 2016; 48: 1688-98. doi: 10.1249/ MSS.0000000000000964

92. Monda V, Villano I, Messina A, Valenzano A, Esposito T, Moscatelli F, et al. Exercise modifies the gut microbiota with positive health effects. Oxid Med Cell Longev 2017; 2017: 3831972. doi: 10.1155/2017/3831972

93. Peters HP, De Vries WR, Vanberge-Henegouwen GP, Akkermans LM. Potential benefits and hazards of physical activity and exercise on the gastrointestinal tract. Gut 2001; 48: 435-39. doi: 10.1136/gut.48.3.435

94. Matsumoto M, Inoue R, Tsukahara T, Ushida K, Chiji H, Matsubara N, et al. Voluntary running exercise alters microbiota composition and increases n-butyrate concentration in the rat cecum. Biosci Biotechnol Biochem 2008; 72: 572-76. doi: 10.1271/bbb.70474

95. Remely M, Aumueller E, Jahn D, Hippe B, Brath H, Haslberger AG. Microbiota and epigenetic regulation of inflammatory mediators in type 2 diabetes and obesity. Benef Microbes 2014; 5: 33-43. doi: 10.3920/BM2013.006

96. Allen JM, Mailing $\sqcup$, Niemiro GM, Moore $R$, Cook MD, White BA, et al. Exercise alters gut microbiota composition and function in lean and obese humans. Med Sci Sports Exerc 2018; 50: 747-57. doi: 10.1249/ MSS.0000000000001495

97. McTiernan A, Friedenreich CM, Katzmarzyk PT, Powell KE, Macko R, Buchner D, et al.; 2018 Physical Activity Guidelines Advisory Committee. Physical activity in cancer prevention and survival: a systematic review. Med Sci Sports Exerc 2019; 51: 1252-61. doi: 10.1249/MSS.0000000000001937 